Historic, Archive Document

Do not assume content reflects current scientific knowledge, policies, or practices. 


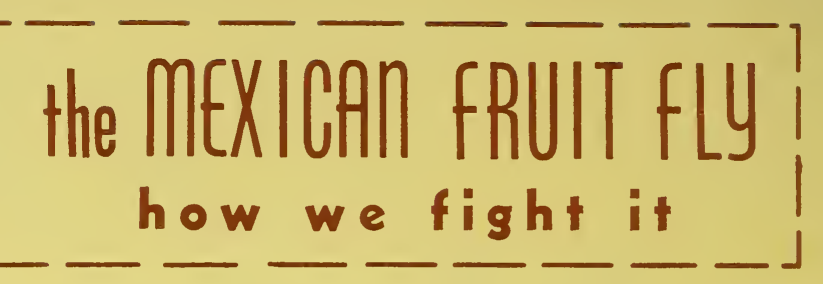

The Mexican fruit fly ${ }^{1}$ attacks citrus and many other types of fruits. The female fly lays eggs just beneath the skin of the fruit. The eggs hatch into larvae. The larvae burrow into the fruit, making it inedible.

Each fall thousands of the flies migrate northward out of northeastern Mexico into southern Texas, where they infest citrus groves in the lower Rio Grande Valley. This is the only place in the United States where the insect is active.

In Mexico the fly attacks grapefruit, oranges, mangoes, apples, peaches, pears, pomegranates, quinces, white sapotes, wild yellow chapotes, and other fruits.

In Texas the fly attacks grapefruit, for which it shows a strong preference, and oranges. Few other host plants of the insect are grown in the lower Rio Grande Valley.

All fruitgrowers should know the facts about the Mexican fruit fly-particularly about the efforts being made to prevent its spreading farther into the United States, and what the consequences would be if it should spread widely despite these efforts.

\section{ORIGIN AND SPREAD}

The Mexican fruit fly is native to northeastern Mexico. Originally it attacked wild fruits of no economic importance. When cultivation of mangoes and citrus and deciduous fruits began in Mexico, the fly also laid eggs in the cultivated fruits.

The fly was discovered in southern Texas in 1927. Here, in the lower Rio Grande Valley, it infests citrus groves in the counties of Brooks, Cameron, Dimmit, Hidalgo, La Salle, Webb, Willacy, and Jim Wells.

\footnotetext{
${ }^{1}$ Anastrepha ludens.
} 
Sterilization of infested fruit by Texas shippers before shipment to other parts of the United States has prevented spread of the insect from the lower Rio Grande Valley. But the insect has spread in Mexico-from the northeastern region to the west coast, and thence northward toward Arizona and California.

In 1953 a well-established infestation was discovered near Hermosillo, Sonora, Mexico-only 185 miles south of the Arizona border. Further spread into Sonora, and into Baja California, occurred in 1954. It was caused chiefly by the shipment of infested fruit from other parts of Mexico.

In August 1954 one of the flies was trapped in San Ysidro, San Diego County, Calif. This was the first Mexican fruit fly ever trapped in the United States outside of the infested area in Texas.

\section{LIFE STAGES}

The Mexican fruit fly has four life stages-egg, larva (maggot), pupa, and adult (fly).

The female fly pierces the skin of the fruit with a long, needlelike ovipositor, and deposits 1 to 10 eggs or more in the area just beneath the skin.

The eggs hatch into larvae. As they grow, the larvae burrow deeply into the flesh of the fruit, and ruin it.

When the larvae mature they leave the fruit, which by that time has usually fallen from the tree. They crawl a short distance, burrow into the soil, and there enter the pupal stage.

The pupae change into flies; the flies emerge from the puparia and work their way to the surface of the soil.

The periods required for hatching of the eggs and for completion of the larval and pupal stages vary with the temperature, variety of fruit, and other conditions. The shortest period in which the egg-to-adult cycle is completed is about 36 days. The insect may produce 4 to 6 generations a year. 



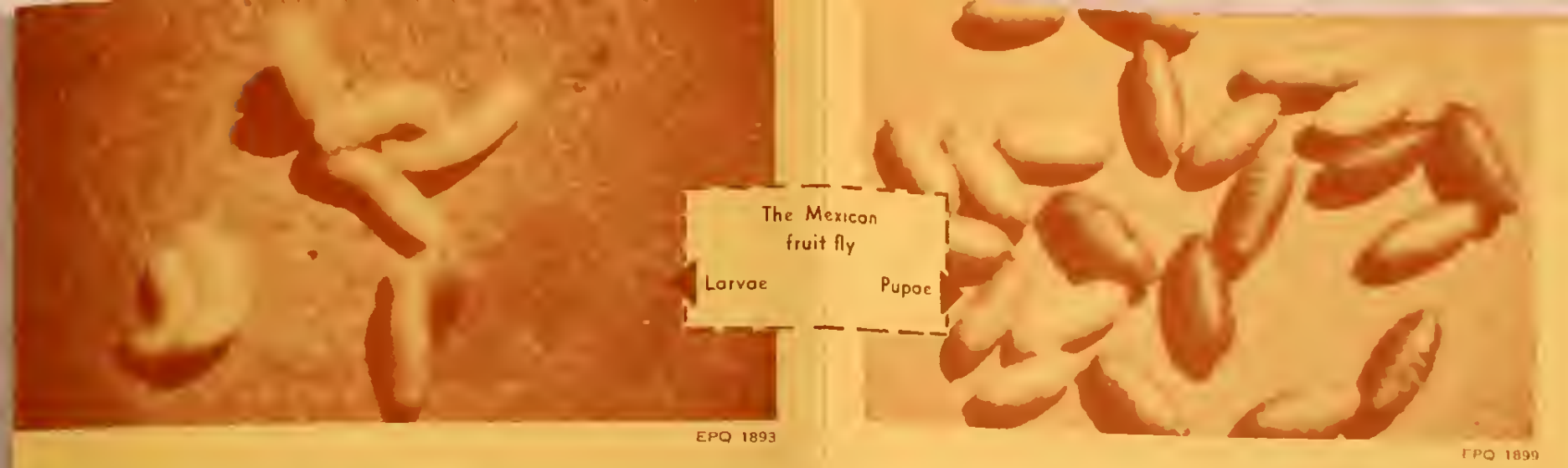

\section{APPEARANCE}

The flies are beautifully colored. They have yellowish-brown bodies and their wings are banded with yellow and brown. They are considerably larger than houseflies.

The larvae are white and have tiny black mouth hooks at the pointed end. They are legless; they move by expanding and contracting the body segments.

\section{HABITS}

The flies do not injure the fruit by feeding on it, but they will feed on the juices from fruit injured in other ways. The larvae do all the damage. One larva in a fruit makes it unfit for food.

The flies can migrate over a large area. They are known to fly 75 to 150 miles from northeastern Mexico to southern Texas. Eggs and immature larvae can survive in fruit shipped over long distances.

So long as host plants are available, the flies can adapt themselves to a variety of conditions. They can withstand freezing weather. They can live in dry or rainy regions, and in mountains or in coastal plains.

The annual migration into southern Texas begins in late fall, when a few flies arrive. As the migration continues, the flies arrive in increasing numbers.

Fly populations build up in January, and peak populations are reached in late March and early April.

Flies infest fruit as long as it remains on the trees. Ordinarily the crop in the lower Rio Grande Valley is moved by June 15, and few mature fruits occur in the Valley until the next citrus season. Without host fruits, the female flies have nowhere to lay their eggs, and the fly population decreases greatly.

\section{INFESTATION SIGNS}

Grapefruit infested by larvae of the Mexican fruit fly take on a light-orange color. There is little else in the appearance of the fruit that serves as a sign of infestation. Infested oranges, however, often develop large brown spots. Each spot shows where larvae have worked within a segment.

Newly hatched larvae are hard to find in citrus fruit, but their presence is indicated frequently by small brown spots in the rag under the skin on each end of the fruit. If such spots are visible, larvae usually can be found within the fruit by cutting off a small portion of the ends of the fruit.

\section{PROTECTIVE MEASURES}

Measures used to fight the Mexican fruit fly and prevent its spread include (1) quarantine programs conducted cooperatively by the United States Department of Agriculture, the Ministry of Agriculture and Livestock of Mexico, and the State departments of agriculture of Texas, California, and Arizona; (2) sterilization of infester fruit before shipment from southern Texas; ancl (3) eradication programs.

Quarantine regulations prohibit movement of unsterilized fruit into the United States from Mexico. Movement of fruit and of host plants into northwestern Mexico from infested sections of that country is subject to Mexican quarantine regulations.

The infested section of Texas has bcen under quarantine regulations since the insect was discovered there. The United States Department of Agriculture supervises the inspection and.sterili- 


\section{EFFECTS OF}

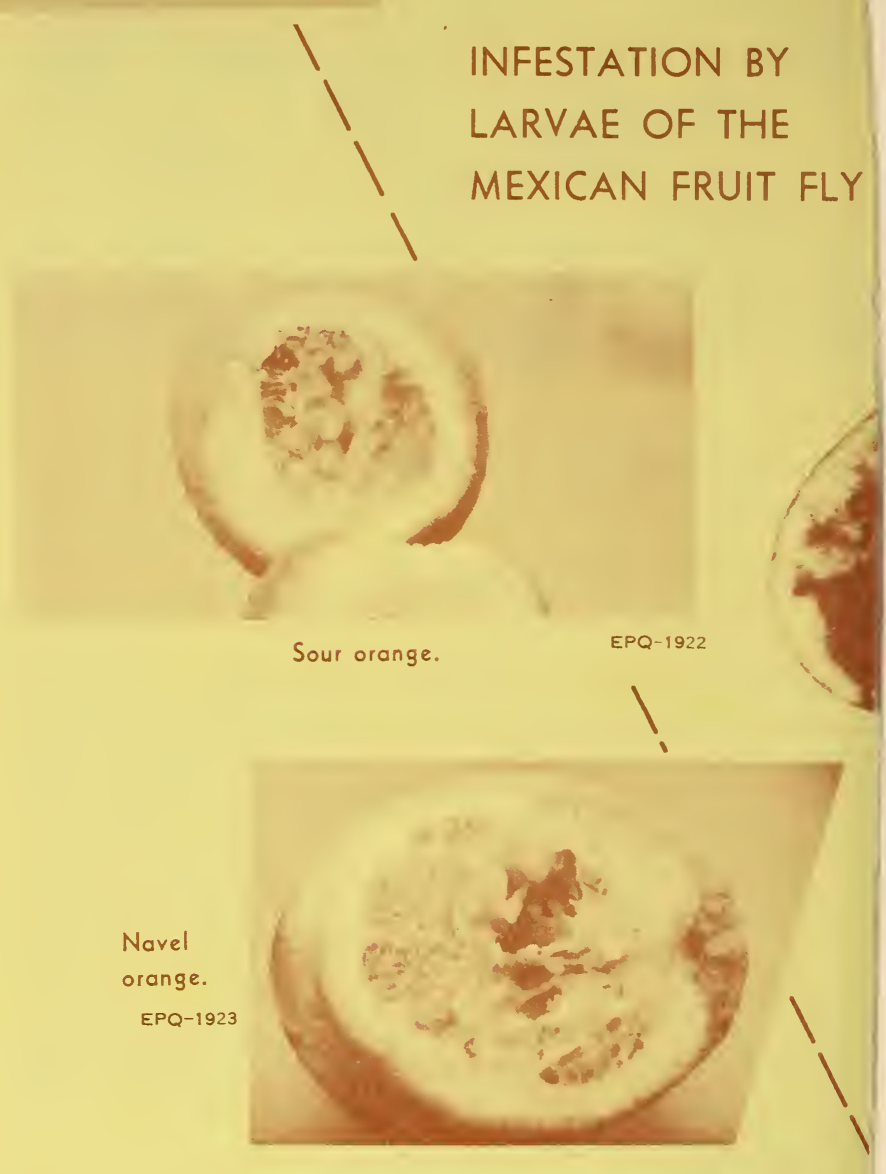

zation of fruit grown in the lower Rio Grande Valley, and the shipment of it to the rest of the country.

By operating traps in the Texas groves, representatives of the Department of Agriculture keep check on whether flies are present. They also make regular inspections of the fruit. When infested fruit is found in a grove, all the fruit in that grove that is to be shipped to points outside the quarantined section must be sterilized.

The vapor-heat process is the sterilization method most widely used in Texas. Sterilization in special treatment rooms raises the inside temperature of the fruit to $110^{\circ} \mathrm{F}$. This kills larvae in the fruit and prevents infested fruit from reaching other fruitgrowing sections.

Although thousands of carloads of fruit are shipped from the infested section of Texas annually, the protective measures followed have been 

Officials of the cooperating national and State governments believe that an intensive spraying program in northern Baja California will wipe out the infestations in that section. This, they believe, will prevent the insect from becoming established in California and Arizona. They point out, however, that inspecting, treating, and regulating the movement of agricultural products over such a large territory is a job that continually taxes their facilities. Road stations and treating plants, and numerous inspectors to man the points of inspection, are necessary to keep the fruit fly out of the United States.

\section{WHAT COULD HAPPEN}

An outbreak of the Mexican fruit fly could occur at any time in the United States, even though all known measures are being taken to prevent this. Chance of an outbreak increases every time a preventive measure is violated, innocently or wilfully.

California, Arizona, and Florida are especially vulnerable to attack. If the fly became established in Arizona, in Florida, or in southern Californiaheart of California's vast fruit-producing section-it probably would cause heavier losses than it does in southern Texas because more varieties of host fruits are grown in these States than in southern Texas. If the fly became established in citrus sections of these States, it would infest grapefruit more readily than oranges. In the absence of grapefruit, the fly would infest oranges heavily. Peaches and pears would also be favored hosts. In southern Florida, mangoes would be attacked heavily.

Fruitgrowers would suffer extensive losses. In addition, large-scale spraying and sterilization programs, plus rigid quarantine regulations, would affect the entire fruitgrowing operation and increase production costs.

Individual fruitgrowers can help fight the Mexican fruit fly by cooperating with public control agencies. Agricultural authorities, knowing that cooperation is based on understanding, have sought to make clear that the protective measures adopted by the States and by the Federal Government are necessary to prevent the fly from invading some of the most productive fruit sections of the United States.

Prepared by the Plant Pest Control Branch, Agricultural Research Service

Washington, D. C.

Issued July 1955

U. S. GOVERNMENT PRINTING OFFICE : 1955-O-338678 